\title{
Defining Optimized Properties of Modified mRNA to Enhance Virus- and DNA- Independent Protein Expression in Adult Stem Cells and Fibroblasts
}

\author{
Frauke Hausburga Silke Naßa Natalia Voronina ${ }^{a}$ Anna Skorska ${ }^{a}$ Paula Müller \\ Gustav Steinhoffa Robert David ${ }^{a}$
}

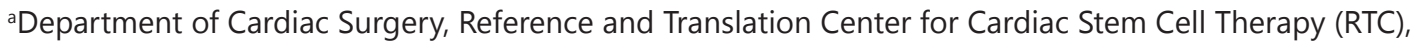
University of Rostock, Rostock, Germany

\section{Key Words}

Modified mRNA • Non-viral $\cdot$ DNA-free $\cdot$ Adult stem cells $\bullet$ Fibroblasts $\bullet$ Trans-differentiation - Reprogramming

\begin{abstract}
Background: By far, most strategies for cell reprogramming and gene therapy are based on the introduction of DNA after viral delivery. To avoid the high risks accompanying these goals, non-viral and DNA-free delivery methods for various cell types are required. Methods: Relying on an initially established PCR-based protocol for convenient template DNA production, we synthesized five differently modified EGFP mRNA (mmRNA) species, incorporating various degrees of 5-methylcytidine-5'-triphosphate $(5 \mathrm{mC})$ and pseudouridine-5'-triphosphate $(\Psi)$. We then investigated their effect on i) protein expression efficiencies and ii) cell viability for human mesenchymal stem cells (hMSCs) and fibroblasts from different origins. Results: Our protocol allows highly efficient mmRNA production in vitro, enabling rapid and stable protein expression after cell transfection. However, our results also demonstrate that the terminally optimal modification needs to be defined in pilot experiments for each particular cell type. Transferring our approach to the conversion of fibroblasts into skeletal myoblasts using mmRNA encoding MyoD, we confirm the huge potential of mmRNA based protein expression for virus- and DNA-free reprogramming strategies. Conclusion: The achieved high protein expression levels combined with good cell viability not only in fibroblasts but also in hMSCs provides a promising option for mmRNA based modification of various cell types including slowly proliferating adult stem cells. Therefore, we are confident that our findings will substantially contribute to the improvement of efficient cell reprogramming and gene therapy approaches.
\end{abstract}

Copyright (C) 2015 S. Karger AG, Basel 


\section{Cellular Physiology \\ and Biochemistry}

Cell Physiol Biochem 2015;35:1360-1371

\begin{tabular}{l|l}
\hline DOI: $10.1159 / 000373957$ & (c) 2015 S. Karger AG, Basel
\end{tabular}

\begin{tabular}{l|l} 
Published online: February 12, 2015 & www.karger.com/cpb
\end{tabular}

Hausburg et al.: Modified mRNA Optimization for Cell Reprogramming

\section{Introduction}

At present, there are promising approaches for reprogramming somatic cells into induced pluripotent stem cells (iPSC) [1] or directly enter the fate to another cell type of interest [2-6]. However, these strategies based on the introduction of DNA and are combined with a viral delivery method. In consequence, they bear high risks (e.g. integration into the genome, systemic distribution) and safety as well as ethical concerns give rise to reconsider these approaches for clinical use.

So far, recent progress in the field of modified mRNA has led to a widely usable tool for different applications based on this DNA-free delivery method.

Injection of in vitro synthesized, yet unmodified mRNA in lower vertebrate embryos such as fish and frog $[7,8]$ has been used as a standard approach in developmental biology for long. While mRNA based target gene expression was reported in 1990 after injection into mouse muscle in vivo [9], its use for mammalian cells and tissues has been hampered by the instability and inefficiency of unmodified mRNA in latter.

Meanwhile, vaccination of autologous dendritic cells, where antigen-encoding transcripts were delivered in vivo, yield plenty of benefits [10-14], e.g. in the field of cancer immunotherapy and for therapeutic vaccination against HIV-1. mRNA-mediated reprogramming of fibroblasts to iPSCs $[15,16]$ results in cells with a global transcriptional signature more closely resembling that of human embryonic stem cells (ESCs) than retrovirally generated iPSCs [15]. Furthermore, it turns out that modified mRNA is a useful basis for gene therapy as an alternative to virus- and DNA-based applications. In this regard, Kormann and colleagues [17] were able to show the improvement of lung function and animal survival after local mRNA application. Therefore, mRNAs encoding therapeutic proteins have great relevance for clinical usage [18].

These achievements have become possible thorough improvement of mRNA properties. Synthesized mRNA possess cis-acting structural elements, such as the 5'-cap, a methylated 3'-0-Me-m7G(ppp)G RNA cap structure analog and a poly-A-tail which are important for mRNA splicing, stabilization and transport [19]. While the features are also important for injections into lower vertebrate embryos (see above), the replacement of both pyrimidines (cytidine and uridine) or only one of them, with 5-methylcytidine-5'-triphosphate $(5 \mathrm{mC})$ and pseudouridine-5'-triphosphate $(\Psi)$ have resulted in a lower immune response in vivo in mammalians $[17,18,20-23]$. The innate immune system is activated through pathogenic mRNA leading to inflammatory response and apoptosis. The incorporation of modified nucleosides and modulation by cis-acting structural elements reduced the stimulation of Toll-like receptors (TLR) [22], protein kinase PKR [24] and retino acid-inducible protein I (RIG-I) [25].

Here, we investigated the effects of $5 \mathrm{mC}$ - and $\Psi$ - incorporation with a focus on protein expression efficiencies between various fibroblast cell lines and bone marrow derived human mesenchymal stem cells (hMSC). We found significant differences between a complete replacement of both pyridmidines and the exchange of only one nucleotide.

Based on these findings, we describe a robust PCR-based in vitro transcription (IVT) approach to reproducibly generate modified mRNA in vitro with functional properties optimized for various cell types thereby leading to rapid and stable protein expression. This is evident from efficient reprogramming of fibroblasts into skeletal muscle like cells. Bone marrow derived hMSCs represent a promising therapeutic tool in tissue regeneration due to their multipotent differentiation potential (e.g. osteocytes, chondrocytes and adipocytes) [26]. By their ability to secrete cytokines and growth factors they show e.g. immunsuppressive-, anti-inflammtory-, anti-apoptotic effects and are able to induce proliferation and differentiation of progenitor cells [27-29]. Furthermore, MSC-based cell therapy shows clinically effective potential in cardiovascular applications like improvement of ventricular volume, infarction size, ejection fraction and myocardial perfusion, which was demonstrated in several human clinical trials [30-32].

We expect our work to become of significant importance for the fields of cell reprogramming and gene therapy. 


\section{Cellular Physiology and Biochemistry}

Cell Physiol Biochem 2015;35:1360-1371

\begin{tabular}{l|l}
\hline DOI: $10.1159 / 000373957$ & (C) 2015 S. Karger AG, Basel
\end{tabular}

\begin{tabular}{l|l} 
Published online: February 12, 2015 & www.karger.com/cpb \\
\hline
\end{tabular}

Hausburg et al.: Modified mRNA Optimization for Cell Reprogramming

\section{Materials and Methods}

Generation of DNA Template for IVT

For DNA template production, pCS2+ expression vector containing SP6 RNA polymerase promoter was used. The EGFP and MyoD coding regions, were amplified with PCR using the forward primer 5'-GTCGGAGCAAGCTTGATTAGG-3' and reverse primer 5'-T ${ }_{100}$ GTCTGGATCTACGTAATACG-3'. The PCR reaction was performed using Herculase enhanced proof-reading DNA polymerase (Agilent Technologies, USA) and the following cycle conditions: initial denaturation at $95^{\circ} \mathrm{C}$ for $2 \mathrm{~min}, 30$ cycles with denaturation at $95^{\circ} \mathrm{C}$ for $30 \mathrm{~s}$, annealing at $59^{\circ} \mathrm{C}$ for $60 \mathrm{~s}$, elongation at $72^{\circ} \mathrm{C}$ for $30 \mathrm{~s}$ and a final elongation step at $72^{\circ} \mathrm{C}$ for $10 \mathrm{~min}$. PCR purification was performed using the peqGOLD Cycle-Pure Kit (peqlab, UK) following the manufacturer's instructions. Purity and concentration was analyzed with a NanoDrop 1000 Spectrophotometer (Thermo Fisher Scientific Inc., USA).

In-vitro synthesis of modified mRNA

In-vitro transcription (IVT) was performed using the MEGAscript SP6 Kit (Ambion, USA) with 500 ng purified EGFP DNA template. To produce mRNA modifications, modified ribonucleoside triphosphates were used during IVT performance. Uridine-triphosphate and cytidine-triphosphate were replaced with pseudouridine-5'-triphosphate and 5-methylcytidine-5'-triphosphate (both TriLink Biotechnologies, USA) in the indicated ratio. EGFP mRNA modifications used in this paper were: unmodified mRNA, 100\% 5-methylcytidine-5'-triphosphate, $\quad 100 \%$ pseudouridine-5'-triphosphate, 52\% 5-methylcytidine-5'triphosphate $+52 \%$ pseudouridine-5'-triphosphate and 100\% 5-methylcytidine-5'-triphosphate $+100 \%$ pseudouridine-5'-triphosphate with a final concentration of $5 \mathrm{mM}$ per nucleotide. To obtain capped mRNA, a $3^{\prime}-0-M e-m 7 G(p p p) G$ RNA cap structure analog (New England Biolabs, USA) was added through the IVT reaction while reducing guanosine-triphosphate in a ratio of $4: 1$. The reaction was incubated for $4 \mathrm{~h}$ at $37^{\circ} \mathrm{C}$. The IVT reaction was treated with TurboDNase (MEGAscript SP6 Kit) for $15 \mathrm{~min}$ at $37^{\circ} \mathrm{C}$ to remove remaining DNA templates. Same procedure was performed for MyoD modified mRNA with the incorporation of $100 \%$ 5-methylcytidine-5' -triphosphate $+100 \%$ pseudouridine-5'-triphosphate.

The mRNA was purified using the GeneJET RNA Purification Kit (Thermo Fisher Scientific Inc., USA) following the manufacturer's instructions. Purity and concentration was analyzed with a NanoDrop 1000 Spectrophotometer.

\section{Cell culture}

Culture of fibroblast cell lines. The monkey kidney COS7 fibroblast line and the mouse embryonic C3H10T1/2 (Clone 8, ATCC, USA) were cultured in DMEM (Biochrom AG, Germany) supplemented with 10\% FBS (Pan Biotech GmbH, Germany), 1\% non-essential amino acids (Biochrom AG, Germany), and 1\% penicillin/streptomycin (PAA Laboratories GmbH, Germany). Mouse embryonic C3H10T1/2 cells were used in passages 13-15.

BJ human foreskin fibroblasts (Stemgent, Cambridge, USA) were cultured in EMEM (Biochrom AG, Germany) supplemented with 10\% FBS (Pan Biotech GmbH, Germany), 1\% non-essential amino acids (Biochrom AG, Germany), and 1\% penicillin/streptomycin (PAA Laboratories GmbH, Germany). BJ human fibroblasts were used in passages 15-25.

Culture of hMSCs. hMSCs were obtained from bone marrow aspirates of patients during coronary artery bypass grafting as previously described [33]. All donors gave their written consent to use their bone marrow for research proposes according to the Declaration of Helsinki. At first, density gradient centrifugation was performed to isolated mononuclear cells. For plastic adherence selection cells were cultivated in Mesenchymal Stem Cell Growth Medium (MSCGM ${ }^{\mathrm{TM}}$, Lonza, Walkersville, MD, USA) containing $100 \mathrm{U} / \mathrm{mL}$ penicillin (PAA, Coelbe, Germany) and $100 \mu \mathrm{g} / \mathrm{mL}$ streptomycin (PAA) at $37{ }^{\circ} \mathrm{C}$ and $5 \% \mathrm{CO}_{2}$. hMSCs were used in passages 2-4.

\section{Transfection with modified $m R N A$}

Single transfection with modified EGFP mRNA. hMSCs and fibroblasts were detached with trypsin for $5 \mathrm{~min}$ at $37^{\circ} \mathrm{C}$, centrifuged and counted in standard growth medium. They were seeded in a density of 1,5 x $10^{4}$ per $\mathrm{cm}^{2}$ in a 24 well plate. $24 \mathrm{~h}$ after seeding, the cells were transfected using Lipofectamine 2000 transfection reagent (Life Technologies $\mathrm{GmbH}, \mathrm{USA}$ ) according to the manufacturer's instructions. Therefore, 


\section{Cellular Physiology and Biochemistry}

Cell Physiol Biochem 2015;35:1360-1371

\begin{tabular}{l|l}
\hline DOI: $10.1159 / 000373957$ & (C) 2015 S. Karger AG, Basel
\end{tabular}

\begin{tabular}{l|l} 
Published online: February 12, 2015 & www.karger.com/cpb \\
\hline
\end{tabular}

Hausburg et al.: Modified mRNA Optimization for Cell Reprogramming

standard growth medium was replaced with $100 \mu \mathrm{L}$ prewarmed Opti-MEM® I Reduced Serum Medium (Life Technologies, USA). The cells were transfected with 500 ng modified EGFP mRNA. The nucleic acidLipofectamine 2000 mixture was added to the cells and incubated for $4 \mathrm{~h}$ at $37{ }^{\circ} \mathrm{C}, 5 \% \mathrm{CO}_{2}$. The medium was replaced with standard growth medium after the incubation time. Cells were cultured at $37^{\circ} \mathrm{C}$ and $5 \% \mathrm{CO}_{2}$.

Serial transfection with MyoD modified mRNA. C3H10T1/2 mouse fibroblasts were detached with trypsin for 5 min at $37^{\circ} \mathrm{C}$, centrifuged and counted in standard growth medium. Fibroblasts were seeded at a density of $5 \times 10^{3}$ per $\mathrm{cm}^{2}$ in a 24 well plate. $4 \mathrm{~h}$ prior to the first transfection, medium was changed to transfection medium, DMEM supplemented with $200 \mathrm{ng} / \mathrm{mL}$ B18R (eBioscience, USA). Cells were transfected three times with $250 \mathrm{ng}$ modified MyoD mRNA at intervals of $24 \mathrm{~h}$. The medium was changed to transdifferentiation medium $24 \mathrm{~h}$ after the last transfection and the cells were cultured for additional $72 \mathrm{~h}$. Transdifferentiation medium containd DMEM containing 10\% horse serum (Life Technologies, USA), 1\% non-essential amino acids and $1 \%$ penicillin/streptomycin.

Flow cytometry

Flow cytometry analyses were carried out $4 \mathrm{~h}, 12 \mathrm{~h}, 24 \mathrm{~h}, 48 \mathrm{~h}$ and $72 \mathrm{~h}$ after transfection. Therefore, supernatant and cells were collected and fixed with $4 \%$ formaldehyde (Sigma-Aldrich, USA). To examine viability, cells were stained with Near-IR LIVE/DEAD Fixable Dead Cell Stain Kit (MolecularProbes, USA). EGFP expression, viability and mean fluorescence was analysed using BD FACS LSRII flow cytometer (BD Biosciences, Germany) with BD FACSDiva Software 6.1.2 (BD Biosciences, Germany).

\section{Immuncytochemistry}

Immunostaining of transfected COS7, C3H10T1/2, BJ and hMSCs was performed $24 \mathrm{~h}$ after transfection with a FITC conjugated anti-GFP antibody (Abcam ab6662, UK) according to the manufacturer's protocol. Fluorescence was detected with Axiovert 40 CFL (Carl Zeiss, Germany).

mRNA-derived myoblast-like cells were seeded on cover slips and fixed after $24 \mathrm{~h}$ with $4 \%$ formaldehyde (Sigma-Aldrich, USA). Cells were treated with 0,1\% Triton X-100 and blocked with blocking solution (PBS with $0,2 \%$ gelatin, $10 \%$ FBS). Following the staining with primary antibody MyHC (Abcam ab15, UK) at 1:200 dilution, the secondary antibody, Alexa Fluor 647 goat anti-mouse IgG (Life Technologies, USA) was applied at 1:500 dilution. Additionally, the cells were counterstained with Phalloidin-FITC to visualize Actin-positive cells (1:1000; Enzo Life Science, Inc., USA) and DAPI (1:2000, Invitrogen, USA) for nuclei staining. Samples were covered with mounting medium. Images were performed using ELYRA PS.1 LSM 780 confocal microscope (Carl Zeiss, Germany) and ZEN2011 software (Carl Zeiss, Germany).

\section{Statistics}

Statistical analyses were performed using SigmaPlot software version 11.0 (Systat Software Inc., USA). All data are reported as mean \pm SEM. Differences in EGFP expression, dead cells and mean fluorescence were analysed for every time point. Analyses of differences between modified mRNAs were performed after the Normality Test (Shapiro-Wilk) and the Equal Variance Test.

One Way Analysis of Variance (ANOVA) was employed for normally distributed data with equal variance. In case of $\mathrm{p}<0.05$, significantly differing groups were determined using Bonferroni as a post hoc test for multiple comparisons. In case of nonnormally distributed data or unequal variance, One Way Analysis of Variance on Ranks (Kruskal-Wallis) test was employed using Dunn's test for post hoc multiple comparisons. $\mathrm{P}<0.05$. was considered statistically significant.

\section{Results}

\section{Generation of modified EGFP $m R N A$}

To generate a highly reproducible modified mRNA (mmRNA) we established a PCRbased protocol (Fig. 1). For this purpose we used the expression vector pCS2+EGFP [34] which contains an SP6 RNA polymerase promoter upstream of the EGFP coding sequence. To produce the DNA-template for IVT, we amplified the EGFP sequence using a forward primer upstream of SP6 promoter sequence and a reverse primer downstream of the EGFP sequence. In addition, this primer contained a poly(T) overhang of 100 thymidine- 


\section{Cellular Physiology and Biochemistry}

Cell Physiol Biochem 2015;35:1360-1371

\begin{tabular}{l|l}
\hline DOI: $10.1159 / 000373957$ & (C) 2015 S. Karger AG, Basel
\end{tabular}

www.karger.com/cpb

Fig. 1. Flow-chart for the generation of modified EGFP mRNA. Expression vector pCS2+ was used as DNA-template for the amplification of EGFP sequence, using proofreading DNA polymerase and a reverse primer, which contains a poly(T) tail. IVT was performed with the incorporation of $5 \mathrm{mC}$ and $\Psi$ using SP6 RNA polymerase. The modified mRNA could be used after purification for the in-vitro delivery into various cell types.

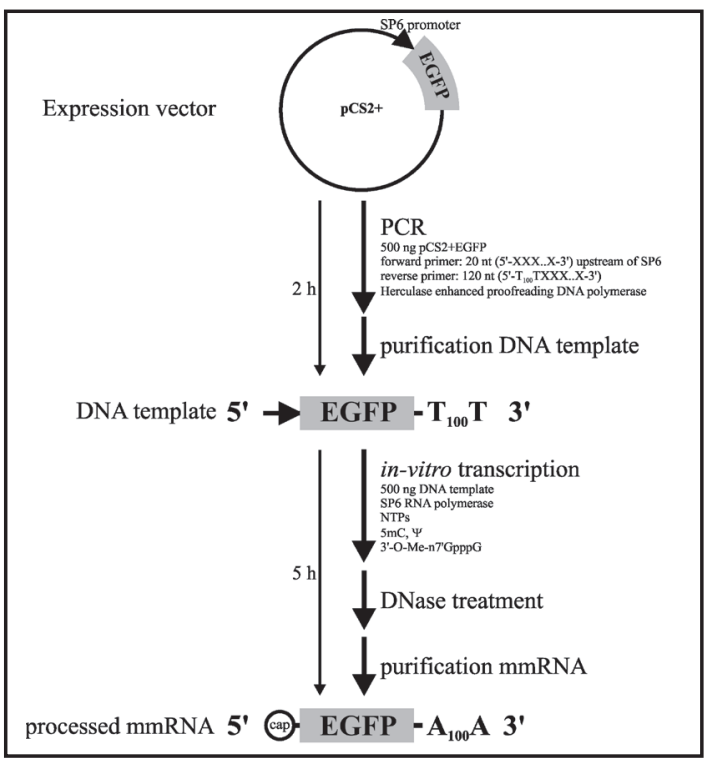

triphospates. IVT was performed using the MEGAscript SP6 Kit. To stabilize the mRNA, we integrated a methylated 3'-0-Me-m7G(ppp)G RNA cap structure analog and modified nucleotides in the IVT reaction. Uridine-triphosphate and cytidine-triphosphate were replaced by pseudouridine-5'-triphosphate and 5-methylcytidine-5'-triphosphate. Therefore, the processed mmRNA contains $3^{\prime}$ an poly(A) tail and is protected with a 5'-cap. We subsequently used this purified mmRNA for the delivery into various cells types.

Optimization of mRNA modification for monkey fibroblasts

In preliminary experiments, the cationic-lipid Lipofectamine2000 had proven to be the most efficient transfection reagent for non-viral delivery of mmRNA (data not shown). It was therefore used in all subsequent experiments.

COS7 cells were used to evaluate the mRNA-mediated protein expression by using different modifications of EGFP mRNA. Transfections were performed $24 \mathrm{~h}$ after cell seeding in a 24 well plate with $500 \mathrm{ng}$ of the respective mRNA modification. EGFP expression, mean fluorescence intensity and cell viability was assessed $4 \mathrm{~h}, 12 \mathrm{~h}, 24 \mathrm{~h}, 48 \mathrm{~h}$ and $72 \mathrm{~h}$ after the transfection with flow cytometric and microscopic analysis. All EGFP modifications led to a fast mRNA-mediated protein expression (between 22,9\% $\pm 5,6$ and $47,7 \% \pm 4,6$ ) after $4 \mathrm{~h}$ with only a significantly lower expression with $100 \% 5 \mathrm{mC}+100 \% \Psi(22,9 \% \pm 5,6)$ compared to unmodified mRNA $(43,5 \% \pm 1,8)$ (Fig. $2 \mathrm{~A})$. The replacement of both pyrimidines led to a significantly higher EGFP expression after $24 \mathrm{~h}(75,3 \% \pm 2,3)$ and stably higher expression levels over time, with a peak after $12 \mathrm{~h}(75,7,5 \% \pm 7,2)$. Likewise, replacement of only $52 \%$ of both pyrimidines led to a significantly higher protein expression after $24 \mathrm{~h}(78,5 \% \pm 4)$ with a peak after $12 \mathrm{~h}(84,6 \% \pm 2,5)$. In contrast, while both $100 \% 5 \mathrm{mC}$ and $100 \% \Psi$ lead to a peak in expression at $12 \mathrm{~h}$, the former $(77,6 \% \pm 4,6)$ is less efficient than the latter $(89,4 \%$ $\pm 2,2$ ). EGFP expression decreases over time using all modifications, but persists at a level of $11,5 \% \pm 2,5-28,1 \% \pm 5,5$ at $72 \mathrm{~h}$. The highest mean fluorescence intensity (Fig. 2B) was detected after $12 \mathrm{~h}$ with $100 \% \Psi$ incorporation, which is also obvious from microscopic analysis (Fig. 2C) after $24 \mathrm{~h}$. $\Psi$-containing mRNA shows a lower percentage of dead cells at all time-points analysed with a statistically significant reduction at $72 \mathrm{~h}(16,5 \% \pm 0,2)$ as compared to the unmodified EGFP mRNA $(34,6 \% \pm 6,1)$. Therefore, we regarded $100 \% \Psi$ and $100 \% 5 \mathrm{mC}+100 \% \Psi$ as the most promising modifications for this cell type.

mmRNA as a tool for cell fate conversion

We next sought to verify our mRNA modifications for various cell lines with the goal to transfer them to functional mmRNA for reprogramming. 
Fig. 2. Transfection of monkey fibroblasts COS7 with modified EGFP mRNA. (A) Percentages of living EGFP expressing cells as measured by flow cytometry. (B) Mean fluorescence intensities as measured by flow cytometry. (C) microscopy images $24 \mathrm{~h}$ after transfection with unmodified, $100 \%$ $5 \mathrm{mC}, \quad 100 \% \quad \Psi, \quad 52 \%$ $5 \mathrm{mC}+52 \% \Psi, 100 \%$ $5 \mathrm{mC}+100 \% \Psi$ and transfection reagent (Lipofectamine2000) as control, stained with FITC-conjugated antiGFP antibody. Scale bar $100 \mu \mathrm{m}$ (D) Percentages of dead cells. Data represent mean \pm SEM, $n$ $=3$. Statistics was performed in multiple comparisons versus unmodified mRNA: * $\mathrm{p}<0.05$, ** $\mathrm{p}<0.01$ and versus untransfected cells: \# $\mathrm{p}<0.05$, \#\# $\mathrm{p}<0.01$, \#\#\# $\mathrm{p}<0.005$.
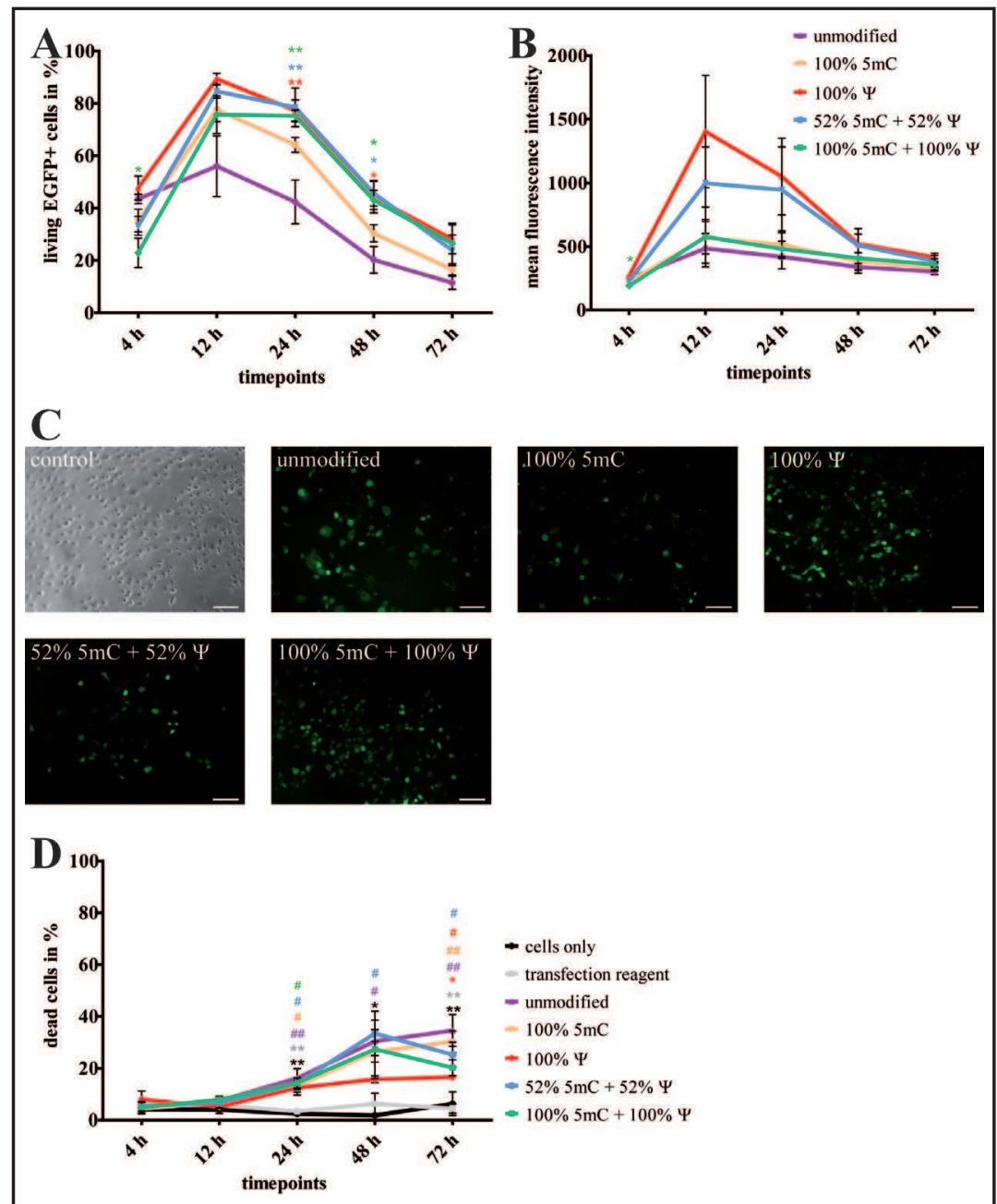

To this end, we first selected murine C3H10T1/2 cells as an established in vitro system for transdifferentiation into skeletal myoblasts [35]. To ensure optimal mRNA-mediated protein expression combined with the highest cell viability, we initially tested the efficiency of unmodified, $100 \% 5 \mathrm{mC}, 100 \% \Psi, 52 \% 5 \mathrm{mC}+52 \% \Psi$ and $100 \% 5 \mathrm{mC}+100 \% \Psi$ EGFP mRNA modifications again, before transferring the best modification to functional mRNA encoding MyoD (see below). It turned out, that the transfection efficiency (Fig. 3) of these cells is much lower within all tested mRNA modifications, with a maximum after $12 \mathrm{~h}$ for all modifications. $100 \% \Psi$ reached the highest EGFP expression with $56,2 \% \pm 11,8$. All modifications show a similar trend of protein expression over time with no statistically difference compared to unmodified mRNA (Fig. 3A). There is almost no EGFP expression detectable after $72 \mathrm{~h}$, whereby $100 \% 5 \mathrm{mC}+100 \% \Psi$ shows the highest expression with $7,7 \% \pm 4,2.100 \% 5 \mathrm{mC}$ reveals the lowest mean fluorescence intensity of all modification (Fig. 3B) and shows nearly the same low amount of dead cells like unmodified mRNA (Fig. 3D). 100\% $\Psi, 52 \% 5 \mathrm{mC}+$ $52 \% \Psi$ and $100 \% 5 \mathrm{mC}+100 \% \Psi$ lead to a higher percentage of dead cells at time-points $4 \mathrm{~h}, 12 \mathrm{~h}, 24 \mathrm{~h}$ and $48 \mathrm{~h}$ (Fig. 3D), although without a statistically significant difference to the unmodified mRNA, but with a significant difference to untransfected cells. Only during long term cultivation of $\mathrm{C} 3 \mathrm{H} 10 \mathrm{~T} 1 / 2(72 \mathrm{~h}) 100 \% 5 \mathrm{mC}+100 \% \Psi$ leads to the lowest viability in comparison with all mRNA modifications and moreover, without any statistically difference to untransfected cells.

To transfer our findings described above to direct cell conversion induced by mmRNA we synthesized MyoD [35] mRNA with the incorporation of $100 \% 5 \mathrm{mC}+100 \% \Psi$ which had 


\section{Cellular Physiology $\quad$ Cell Physiol Biochem 2015;35:1360-1371 \begin{tabular}{l|l|l} 
DOI: 10.1159/000373957 & O 2015 S. Karger AG, Basel
\end{tabular} and Biochemistry Published online: February 12, 2015 www.karger.com/cpb

Fig. 3. Transfection of murine fibroblasts C3H10T1/2 with modified EGFP mRNA. (A) Percentages of living EGFP expressing cells as measured by flow cytometry. (B) Mean fluorescence intensities as measured by flow cytometry. (C) microscopy images $24 \mathrm{~h}$ after transfection with unmodified, $100 \% 5 \mathrm{mC}, 100 \%$ $\Psi, 52 \% 5 \mathrm{mC}+52 \% \Psi$, $100 \% 5 \mathrm{mC}+100 \% \Psi$ and transfection reagent (Lipofectamine2000) as control, stained with FITC-conjugated antiGFP antibody. Scale bar $100 \mu \mathrm{m}$ (D) Percentage of dead cells. Data represent the mean $\pm \mathrm{SEM}$, $\mathrm{n}=3$. Statistics was performed in multiple comparisons versus unmodified mRNA: * $\mathrm{p}<0.05$, ** $\mathrm{p}<0.01$ and versus untransfected cells: \# $\mathrm{p}<0.05$, \#\# p<0.01, \#\#\# $\mathrm{p}<0.005$.

Fig. 4. Cell fate conversion induced by modified MyoD mRNA. (A) Flow chart for direct cell reprogramming of C3H10T1/2 fibroblasts, cells were seeded (5 $\times 10^{3}$ cells $\left./ \mathrm{cm}^{2}\right)$ in standard growth medium. Transfection was performed with $250 \mathrm{ng}$ mMyoD mRNA three times (every $24 \mathrm{~h}$ ) in transfection medium supplemented with B18R. Additional cultivation was performed for three days in serum reduced medium.
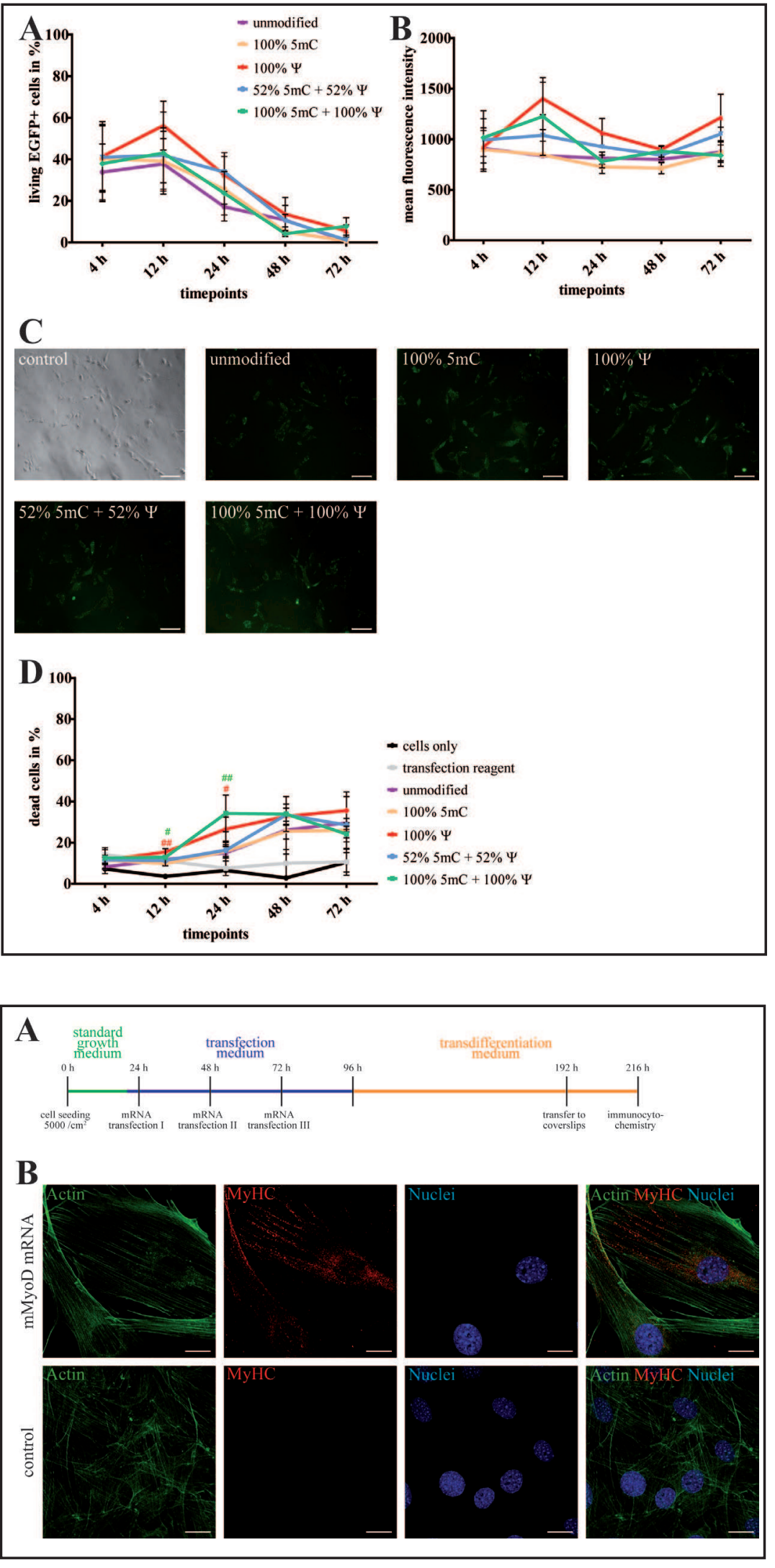

(B) mRNA-derived myoblast-like cells, expression of the muscle marker myosin heavy chain (MyHC) in C3H10T1/2 cell derivatives after transfection with mMyoD mRNA and negative control. Scale bar $20 \mu \mathrm{m}$. 
Fig. 5. Transfection of human fibroblasts BJ with modified EGFP mRNA. (A) Percentages of living EGFP expressing cells as measured by flow cytometry. (B) Mean fluorescence intensities as measured by flow cytometry. (C) microscopy images $24 \mathrm{~h}$ after transfection with unmodified, $100 \% 5 \mathrm{mC}, 100 \%$ $\Psi, 52 \% 5 \mathrm{mC}+52 \% \Psi$, $100 \% 5 \mathrm{mC}+100 \% \Psi$ and transfection reagent (Lipofectamine 2000) as control, stained with FITC-conjugated antiGFP antibody. Scale bar $100 \mu \mathrm{m}$ (D) Percentage of dead cells. Data represent the mean \pm SEM, $n$ = 3-4. Statistics was performed in multiple comparisons versus unmodified mRNA: * $\mathrm{p}<0.05$, ** $\mathrm{p}<0.01$ and versus untransfected cells: \# $\mathrm{p}<0.05$, \#\# p<0.01, \#\#\# $\mathrm{p}<0.005$.
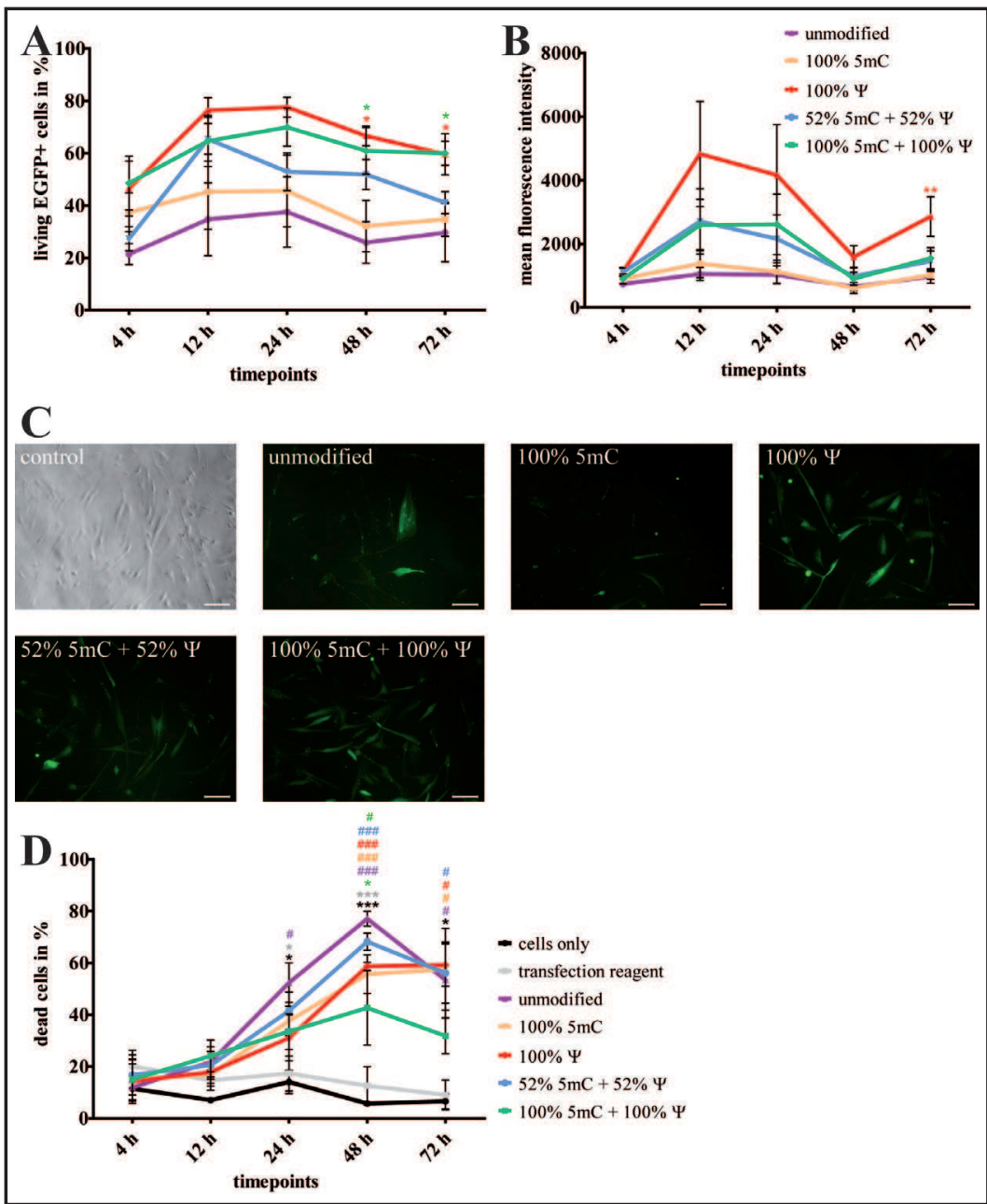

proven most promising for murine C3H10T1/2 because of the best cell viability during long term cultivation combined with a high transfection efficiency and good fluorescence intensity. The cells were transfected three times in an interval of $24 \mathrm{~h}$ (Fig. 4A) and transfection medium was supplemented with the recombinant protein B18R [36], to increase cell viability. This was followed by an incubation time of three days in serum reduced medium. Thereafter, mRNA-derived myoblast-like cells were found, which typically expressed myosin heavy chain (MyHC) (Fig. 4B) thereby demonstrating the ability to directly alter cell identity with our optimized mmRNA.

Transfer to human fibroblasts and human mesenchymal stem cells

To bring our non-viral and DNA-free delivery method closer to the clinic, we explored the transfection efficiency of modified mRNA on using two human cell types: the fibroblast cell line BJ as well as bone marrow derived human mesenchymal stem cells.

EGFP expression based on $100 \% \Psi$ after $24 \mathrm{~h}$ in human BJs (Fig. 5A; 77,6\% $\pm 3,8$ ) reached nearly the same level as in COS7 (Fig. 2A) and shows the highest mean fluorescence after $12 \mathrm{~h}$ (Fig. 6B). In addition, 100\% $\Psi$ leads to a significantly higher mean fluorescence compared to the unmodified mRNA after $72 \mathrm{~h}$. In contrast, $100 \% 5 \mathrm{mC}$ shows no significant improvements in protein expression and mean fluorescence compared to the unmodified EGFP mRNA. Furthermore, $100 \% 5 \mathrm{mC}(55,6 \% \pm 11,9)$ and $52 \% 5 \mathrm{mC}+52 \% \Psi(68,2 \% \pm 1,5)$ lead to the highest percentages of dead cells after $48 \mathrm{~h}$ (Fig. 6D). However, complete replacement of both pyrimidines leads to a higher cell viability over the time and to no significant difference after $72 \mathrm{~h}$ compared to untransfected control.

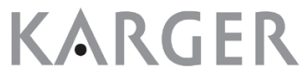


Fig. 6. Transfection of human mesenchymal stem cells with modified EGFP mRNA. (A) Percentages of living EGFP expressing cells as measured by flow cytometry. (B) Mean fluorescence intensities as measured by flow cytometry. (C) microscopy images $24 \mathrm{~h}$ after transfection with unmodified, $100 \% \Psi$, $100 \% 5 \mathrm{mC}+100 \% \Psi$ and transfection reagent (Lipofectamine2000) as control, stained with FITC-conjugated anti-GFP antibody. Scale bar $100 \mu \mathrm{m}$ (D) Percentage of dead cells. Data represent the mean \pm SEM, $n=3-4$ (6 patients). Statistics was performed in multiple comparisons versus unmodified mRNA: ${ }^{*} \mathrm{p}<0.05,{ }^{* *} \mathrm{p}<0.01$ and versus untransfected cells: \# p<0.05, \#\# p<0.01, \#\#\# $\mathrm{p}<0.005$.

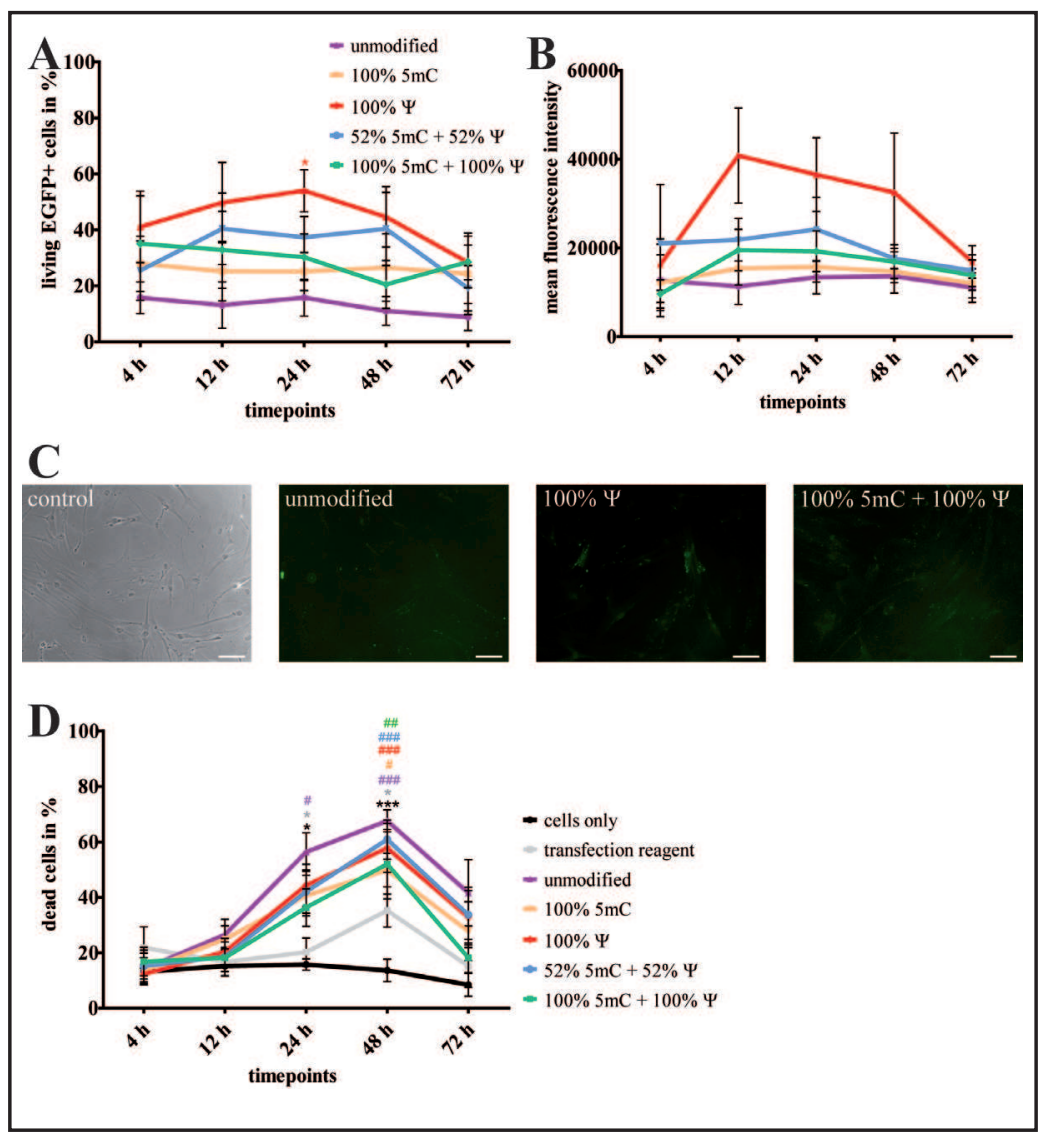

As opposed to the tested fibroblast cell lines (Fig. 2A, 3A and 5A), 100\% $\Psi$ showed clearly the highest mRNA-mediated protein expression (Fig. 6A) and mean fluorescence intensity (Fig. 6B) at all time-points in MSCs. Moreover, cell viability is higher compared to unmodified mRNA (Fig. 6D). Remarkably, protein expression appears very rapidly

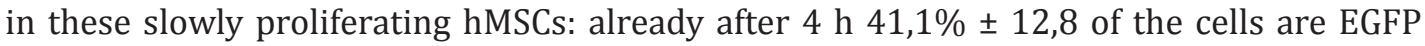
positive, reaching a peak after $24 \mathrm{~h}$ with $54 \% \pm 6,5$. Even with MSCs $100 \% 5 \mathrm{mC}$ shows no significant difference in protein expression and mean fluorescence compared to unmodified mRNA candidate. However, the combination of $52 \% 5 \mathrm{mC}+52 \% \Psi$ leads to a stable protein expression between $12 \mathrm{~h}(40,4 \% \pm 12,8)$ and $48 \mathrm{~h}(40,3 \% \pm 13)$ but reveals as well as all modifications a significantly difference of dead cells to untransfected control. The highest amount of dead cells appears with unmodified mRNA ( $56 \% \pm 8,9$ after $24 \mathrm{~h}$ and $67,9 \% \pm 4$ after $48 \mathrm{~h}$ ).

\section{Discussion}

In this study, we demonstrated that non-viral delivery of in vitro synthesized modified mRNA is a promising approach for highly efficient target gene expression in several cell types including adult bone marrow derived stem cells. To this end, we initially introduced five different modifications in EGFP-mRNA to define the optimal parameters, with the ultimate goal to transfer these to functional modified mRNA for cell reprogramming. Moreover, we succeeded in establishing a protocol to generate highly reproducible modified mRNA, based on DNA-template generation via polymerase chain reaction using proof-reading polymerase.

As claimed before by Warren et al. [15], the complete replacement of both pyrimidines (cytidine and uridine) led to a significantly higher EGFP expression compared to unmodified 


\section{Cellular Physiology and Biochemistry}

Cell Physiol Biochem 2015;35:1360-1371

\begin{tabular}{l|l}
\hline DOI: $10.1159 / 000373957$ & (C) 2015 S. Karger AG, Basel
\end{tabular}

www.karger.com/cpb

Hausburg et al.: Modified mRNA Optimization for Cell Reprogramming

EGFP in all cell types. However, our results revealed that the terminally optimal modification is cell type dependent which has to be taken in account for future applications.

Moreover, we included cell viability for long term cultivation as an additional crucial parameter, yet largely neglected factor for mmRNA based reprogramming approaches. In this regard, the complete replacement of both pyrimidines with $100 \% 5 \mathrm{mC}+100 \% \Psi$ turned out as the mildest modification in three different cell types (C3H10T1/2, BJ and hMSC).

However, taking into account our own findings as well as those of others [18, 20], obviously best translation efficiencies can be attributed to the incorporation of $100 \% \Psi$. EGFP mRNA with the exchange of uridine to $\Psi$ leads to the highest expression levels and mean fluorescence intensities in all cell types used by us. Thereby, we did not observe a significant difference in EGFP expression after complete replacement of both pyrimdines versus $100 \% \Psi$ alone in COS7, C3H10T1/2 and human BJ. Only in hMSCs, $100 \% \Psi$ alone leads to higher EGFP expression levels and mean fluorescence intensities compared to the complete replacement. In summary, taking into account translation efficiency combined with cellular viability, we recommend transfection with $100 \% \Psi$ for monkey COS7 and human MSCs, and with $100 \% 5 \mathrm{mC}+100 \% \Psi$ for murine C3H10T1/2 and human BJs. Furthermore, our data reveal that the definitive mmRNA composition needs to be defined in pilot experiments for each cell type to be used.

We next addressed the therapeutic potential of functional mmRNA synthesized according to our findings. To this end, we relied on murine C3H10T1/2 cells as an established in vitro system for the transdifferentiation towards myoblasts [35]. Indeed, using our previously defined incorporation of $100 \% 5 \mathrm{mC}+100 \% \Psi$, we were able to transform these fibroblasts to a myoblast-like phenotype. This reflected in the expression of myosin heavy chain-protein.

Therefore, our mmRNA optimized for C3H10T1/2 cells is clearly functional and our findings may become of great importance for new virus- and DNA-free reprogramming strategies using various cellular sources. In particular, the possibility to reach high protein expression combined with good cells viability in hMSCs provides a promising option for slowly proliferating adult stem cells.

Therefore, we expect our work to open new opportunities in gene therapy and regenerative medicine.

\section{Acknowledgements}

This work has been funded by the Federal Ministry of Education and Research Germany (FKZ 0312138A and FKZ 316159) and the State Mecklenburg-Western Pomerania with EU Structural Funds (ESF /IV-WM-B34-0030/10 and ESF/IV-BM-B35-0010/12), by the DFG ( DA 1296-1) and the German Heart Foundation (F/01/12).

\section{Disclosure Statement}

The authors declare no conflict of interest.

\section{References}

1 Takahashi K, Tanabe K, Ohnuki M, Narita M, Ichisaka T, Tomoda K, Yamanaka S: Induction of pluripotent stem cells from adult human fibroblasts by defined factors. Cell 2007;131:861-72.

2 Zhou Q, Brown J, Kanarek A, Rajagopal J, Melton DA: In vivo reprogramming of adult pancreatic exocrine cells to beta-cells. Nature 2008;455:627-32.

3 Vierbuchen T, Wernig M: Direct lineage conversions: unnatural but useful? Nat. Biotechnol. 2011;29:892907. 


\section{Cellular Physiology and Biochemistry}

Cell Physiol Biochem 2015;35:1360-1371

\begin{tabular}{l|l}
\hline DOI: $10.1159 / 000373957$ & (C) 2015 S. Karger AG, Basel
\end{tabular}

www.karger.com/cpb

Hausburg et al.: Modified mRNA Optimization for Cell Reprogramming

4 Szabo E, Rampalli S, Risueño RM, Schnerch A, Mitchell R, Fiebig-Comyn A, Levadoux-Martin M, Bhatia M: Direct conversion of human fibroblasts to multilineage blood progenitors. Nature 2010;468:521-6.

5 Ieda M, Fu J, Delgado-Olguin P, Vedantham V, Hayashi Y, Bruneau BG, Srivastava D: Direct reprogramming of fibroblasts into functional cardiomyocytes by defined factors. Cell 2010;142:375-86.

6 Qian L, Huang Y, Spencer CI, Foley A, Vedantham V, Liu L, Conway SJ, Fu J, Srivastava D: In vivo reprogramming of murine cardiac fibroblasts into induced cardiomyocytes. Nature 2012;485:593-8.

7 David R, Joos TO, Dreyer C: Anteroposterior patterning and organogenesis of Xenopus laevis require a correct dose of germ cell nuclear factor (xGCNF). Mechanisms of Development 1998;79:137-52.

8 Kriegmair, Maximilian C M, Frenz S, Dusl M, Franz W, David R, Rupp, Ralph A W: Cardiac differentiation in Xenopus is initiated by mespa. Cardiovasc. Res. 2013;97:454-63.

9 Wolff JA, Malone RW, Williams P, Chong W, Acsadi G, Jani A, Felgner PL: Direct gene transfer into mouse muscle in vivo. Science 1990;247:1465-8.

10 Gilboa E, Vieweg J: Cancer immunotherapy with mRNA-transfected dendritic cells. Immunol. Rev. 2004;199:251-63.

11 Pascolo S: Vaccination with messenger RNA (mRNA). Handb Exp Pharmacol 2008:221-35.

12 Van Craenenbroeck, Amaryllis H, Smits, Evelien L J, Anguille S, Van de Velde, Ann, Stein B, Braeckman T, van Camp K, Nijs G, Ieven M, Goossens H, Berneman ZN, Van Tendeloo, Viggo F I, Verpooten GA, van Damme P, Cools N: Induction of Cytomegalovirus-Specific T Cell Responses in Healthy Volunteers and Allogeneic Stem Cell Recipients Using Vaccination With Messenger RNA-Transfected Dendritic Cells. Transplantation 2014.

13 Phua, Kyle K L, Nair SK, Leong KW: Messenger RNA (mRNA) nanoparticle tumour vaccination. Nanoscale 2014;6:7715-29.

14 Pollard C, Koker S de, Saelens X, Vanham G, Grooten J: Challenges and advances towards the rational design of mRNA vaccines. Trends Mol Med 2013;19:705-13.

15 Warren L, Manos PD, Ahfeldt T, Loh Y, Li H, Lau F, Ebina W, Mandal PK, Smith ZD, Meissner A, Daley GQ Brack AS, Collins JJ, Cowan C, Schlaeger TM, Rossi DJ: Highly efficient reprogramming to pluripotency and directed differentiation of human cells with synthetic modified mRNA. Cell Stem Cell 2010;7:618-30.

16 Yakubov E, Rechavi G, Rozenblatt S, Givol D: Reprogramming of human fibroblasts to pluripotent stem cells using mRNA of four transcription factors. Biochem. Biophys. Res. Commun. 2010;394:189-93.

17 Kormann, Michael S D, Hasenpusch G, Aneja MK, Nica G, Flemmer AW, Herber-Jonat S, Huppmann M, Mays LE, Illenyi M, Schams A, Griese M, Bittmann I, Handgretinger R, Hartl D, Rosenecker J, Rudolph C: Expression of therapeutic proteins after delivery of chemically modified mRNA in mice. Nat. Biotechnol. 2011;29:154-7.

18 Karikó K, Muramatsu H, Keller JM, Weissman D: Increased erythropoiesis in mice injected with submicrogram quantities of pseudouridine-containing mRNA encoding erythropoietin. Mol. Ther. 2012;20:948-53.

19 Quabius ES, Krupp G: Synthetic mRNAs for manipulating cellular phenotypes: an overview. N Biotechnol 2014.

20 Karikó K, Muramatsu H, Welsh FA, Ludwig J, Kato H, Akira S, Weissman D: Incorporation of pseudouridine into mRNA yields superior nonimmunogenic vector with increased translational capacity and biological stability. Mol. Ther. 2008;16:1833-40.

21 Karikó K, Muramatsu H, Ludwig J, Weissman D: Generating the optimal mRNA for therapy: HPLC purification eliminates immune activation and improves translation of nucleoside-modified, proteinencoding mRNA. Nucleic Acids Res. 2011;39:e142.

22 Karikó K, Buckstein M, Ni H, Weissman D: Suppression of RNA recognition by Toll-like receptors: the impact of nucleoside modification and the evolutionary origin of RNA. Immunity 2005;23:165-75.

23 Davis DR: Stabilization of RNA stacking by pseudouridine. Nucleic Acids Res. 1995:5020-6.

24 Nallagatla SR, Bevilacqua PC: Nucleoside modifications modulate activation of the protein kinase PKR in an RNA structure-specific manner. RNA 2008;14:1201-13.

25 Hornung V, Ellegast J, Kim S, Brzózka K, Jung A, Kato H, Poeck H, Akira S, Conzelmann K, Schlee M, Endres S, Hartmann G: 5'-Triphosphate RNA is the ligand for RIG-I. Science 2006;314:994-7.

26 Grassel S, Ahmed N: Influence of cellular microenvironment and paracrine signals on chondrogenic differentiation. Front. Biosci. 2007;12:4946-56.

27 Eggenhofer E, Luk F, Dahlke MH, Hoogduijn MJ: The life and fate of mesenchymal stem cells. Front Immunol 2014;5:148. 
28 Chou S, Lin S, Kuo W, Pai P, Lin J, Lai C, Kuo C, Lin K, Tsai F, Huang C: Mesenchymal stem cell insights: prospects in cardiovascular therapy. Cell Transplant 2014;23:513-29.

29 Kim N, Cho S: Clinical applications of mesenchymal stem cells. Korean J. Intern. Med. 2013;28:387-402.

30 Chen S, Fang W, Ye F, Liu Y, Qian J, Shan S, Zhang J, Chunhua RZ, Liao L, Lin S, Sun J: Effect on left ventricular function of intracoronary transplantation of autologous bone marrow mesenchymal stem cell in patients with acute myocardial infarction. The American journal of cardiology 2004;94:92-5.

31 Hare JM, Traverse JH, Henry TD, Dib N, Strumpf RK, Schulman SP, Gerstenblith G, DeMaria AN, Denktas AE, Gammon RS, Hermiller JB, Reisman MA, Schaer GL, Sherman W: A randomized, double-blind, placebocontrolled, dose-escalation study of intravenous adult human mesenchymal stem cells (prochymal) after acute myocardial infarction. Journal of the American College of Cardiology 2009;54:2277-86.

32 Mazhari R, Hare JM: Mechanisms of action of mesenchymal stem cells in cardiac repair: potential influences on the cardiac stem cell niche. Nature clinical practice. Cardiovascular medicine 2007;4 Suppl 1:S21-6.

33 Gaebel R, Furlani D, Sorg H, Polchow B, Frank J, Bieback K, Wang W, Klopsch C, Ong L, Li W, Ma N, Steinhoff G: Cell origin of human mesenchymal stem cells determines a different healing performance in cardiac regeneration. PLoS ONE 2011;6:e15652.

34 David R, Brenner C, Stieber J, Schwarz F, Brunner S, Vollmer M, Mentele E, Müller-Höcker J, Kitajima S, Lickert H, Rupp R, Franz W: MesP1 drives vertebrate cardiovascular differentiation through Dkk-1mediated blockade of Wnt-signalling. Nat. Cell Biol. 2008;10:338-45.

35 Davis RL, Weintraub H, Lassar AB: Expression of a Single Transfected cDNA Converts Fibroblasts to Myoblasts. Cell Press 1987;51:987-1000.

36 Symons JA, Alcamí A, Smith GL: Vaccinia virus encodes a soluble type I interferon receptor of novel structure and broad species specificity. Cell 1995;81:551-60. 